\title{
RESPEITO AOS PRECEDENTES JUDICIAIS ITERATIVOS PELA ADMINISTRAÇÃO PÚBLICA
}

JUAREZ FREITAS*

1. Introduçāo. 2. Da conveniência de a Administração Pública acatar as decisōes judiciais iterativas e pacificadas. 3. Dos limites hermenêuticos aos "precedentes vinculantes" em relação ao próprio Poder Judiciário: a necessária preservação do controle difuso. 4. Conclusões.

\section{Introdução}

O Direito vivo é bem mais do que a lei e é determinado, em instância última, pelo Poder Judiciário, em nome da sociedade que o legitima através do acatamento. A partir desta premissa de fundo, pretende-se sustentar que exsurge, de modo insofismável, do sistema brasileiro a necessidade de a Administração Pública acatar, prontamente, as decisões definitivas ou pacificadas do Poder Judiciário, mormente em sede de pronunciamentos concentrados ou objetivos, nos quais inexiste, a rigor, a clássica contraposição de partes. Ao mesmo tempo, recomenda-se, por razões especialmente de natureza hermenêutica, que se evite a inflação dos referidos precedentes vinculantes (expressão assaz indutora de equívocos, mormente quando aplicada em relação ao próprio Judiciário).

Correm, paralelas, estas idéias centrais, nada antinômicas, sobretudo para quem compreende o modo de operar e de aplicar o Direito, cuja eficácia de seus princípios e regras ${ }^{1}$ nada mais se afigura, em termos contemporâneos, do que a eficácia da interpretação que se imprime a seus múltiplos comandos. Com efeito, no sistema constitucional pátrio, por vários motivos funcionais e competenciais, sem desdouro ou menosprezo ao papel do administrador público (justamente ao revés), é de todo

1 Vide, entre outros, a propósito da distinção entre princípios e regras, Robert Alexy in Theorie der Grundrechte, Suhrkamp, Frankfurt am Maim, 1994, pp. 71-98.

* Professor de Direito Administrativo da UFRGS, do Mestrado de Direito da PUC/RS e da Escola Superior de Magistratura-AJURIS.

R. Dir. Adm., Rio de Janeiro, 211: 117-123, jan./mar. 1998 
conveniente entender que o legislador fecunda e parteja o preceito jurídico, mas incumbe ao julgador efetivar o controle definitivo e cabal de sua adequação e qualidade. Do entendimento claro e da aceitação da intangibilidade deste ciclo, brotarão as inferências e prescrições do presente estudo.

\section{Da conveniência de a Administração Pública acatar as decisões judiciais iterativas e pacificadas}

Com efeito, em Carta pautada pela unicidade da jurisdição (CF, art. $\left.5^{\circ}, \mathrm{XXXV}\right)^{2}$, a Administração Pública precisa, vez por todas, exemplarmente acatar os pronunciamentos irrecorríveis do Poder Judiciário, sob pena de fazer perecer a credibilidade do próprio sistema de controle, dele subtraindo o hálito vital do respeito mútuo e da independência harmônica (arts. $2^{\circ}$ e $60, \S 4^{\circ}$, III da CF). Dentro de limites, deve assumir, em maior grau, o dever de acatar, por exemplo, as decisões definitivas do Supremo Tribunal Federal mormente em sede concentrada, ainda quando a considere politicamente desalinhada. É dizer, sobremodo em vista do controle de constitucionalidade exercitado nos processos objetivos (a saber, na Ação Direta de Inconstitucionalidade e na polêmica Ação Declaratória de Constitucionalidade), tem-se a hipótese de culminar na declaração de inconstitucionalidade objetiva, operando esta com efeito "erga omnes", à diferença do que sucede no quase sempre tardio controle incidental, uma vez que este último se mostra dependente de ato suspensivo do Senado.

$\mathrm{Na}$ seara concentrada, o afastamento do mundo jurídico da norma considerada nula é imediato, em face da aludida mácula fulminante, sendo a mesma escoimada, por inteiro, pelo legislador negativo. Destarte, até em respeito aos princípios da legalidade, da confiança ${ }^{3}$ e da segurança das relações jurídicas, a Administração Pública não pode prosseguir cometendo ou deixando de executar atos administrativos com arrimo e base em lei considerada inconstitucional, justamente pela fortíssima e insuperável circunstância de esta não mais integrar o ordenamento jurídico, toda vez que, em definitivo, suceder decisão da mais Alta Corte no controle concentrado.

$O$ aludido acatamento revela-se de elevada necessidade, outrossim, em resguardo de pelo menos dois outros princípios fundamentais. Sem dúvida, o princípio da moralidade exige que a Administração Pública atue de sorte a se fazer paradigmática no respeito às instituições $\mathrm{e}$ aos cidadãos, não podendo ser a primeira a dar o tenebroso exemplo de litigância de má fé ou de maneirista descaso em relação ao sentido máximo do plexo normativo, emprestado pelo Poder Judiciário. O contrário de tal respeito pode significar, ao menos, o virtual manejo excessivo da imensa gama de recursos, utilizados para não honrar os improteláveis compromissos que a lealdade e a boa fé impõem, tanto no processo quanto fora dele.

2 Sobre o princípio da unicidade da jurisdição e seus desdobramentos, vide meu $O$ Controle dos Atos Administrativos e os Princípios Fundamentais, São Paulo, Malheiros, 1997, pp. 81-85.

3 Vide Norbert Achterberg in Allgemeines Verwaltungsrecht, Lehrbuch, Heidelberg, C.F. Müller Juristicher Verlag, 1982, p. 469. 
De outra parte, o não-acatamento corre o risco de ofender, gravemente, o princípio da economicidade, por duas razões primaciais. Em primeiro plano, porquanto, numa demonstração de suposto zelo, deixa-se de cuidar, no tempo devido, de muitíssimas outras, verdadeiramente ilegítimas, agressões impostas ao abalado erário público. Neste passo e não raro, o combate severo e enérgico contra a sonegação, a improbidade administrativa ou a má-prestação dos serviços públicos resulta debilitado, já que malversadas ou desviadas as melhores energias em postulações ou recursos com o ânimo protelatório ou meramente rotineiro. Assim, desestimula-se a máquina fiscalizadora, compelindo-a a contemplar malabarismos hermenêuticos constrangedores em lugar de fazê-la ativa, exitosa e enérgica no cumprimento dos seus indelegáveis deveres. Em segundo lugar, a morosidade processual, além de se revelar fatal para cidadãos vitimados pela síndrome das vitórias com sabor amargo, acaba sendo dispendiosa e onerosíssima para os cofres públicos. Paga-se - na prática o contribuinte, bem entendido - pesadamente para compensar a tardança apta a produzir danos irreparáveis ou de difícil reparação, sobremodo quando se configura o caráter protelatório ou mesmo a mencionada litigância de má fé. ${ }^{4}$

Pois bem: seria demasiado formalismo adotar atitude diversa em face de pronunciamentos em sede difusa, apenas por carência de manifestação suspensiva do Senado, quando sobre a matéria o Poder Judiciário já tiver iterativa e consolidada posição. Ainda aí, desde que largamente pacificada a orientação, parece lógico o dever, talvez menos intenso em grau (mas ainda assim dever e, como tal, impostergável), de acatamento dos precedentes judiciais e de emissões rápidas de súmulas administrativas confortadoras de tais diretrizes, nos moldes daquelas que se tornam obrigatórias, "ex. vi" dos arts. 4², XII e 43 da Lei Complementar 73/93.

Logo, convém sublinhar, a simples jurisprudência iterativa dos Tribunais fonte material, por excelência, inclusive no sistema romanístico-continental observado o pressuposto de ter florescido sem maiores controvérsias, deve, com as devidas cautelas, ser objeto de eficiente e rápida expedição de súmulas ou de decisão normativa de quem detiver poderes hierárquicos para velar pela conduta processual adequada da Administração, ambas atitudes indispensáveis à harmonia dos poderes e para que o agente público não se converta em triste servo do não-Direito ou da erosão de sua própria credibilidade.

Ademais disso, de "lege ferenda", em tais casos, dever-se-ia evitar o manifesto e indisputável desperdício do reexame necessário, mantendo-o apenas naqueles casos em que se revelar estritamente favorável a equação custo-benefício. Seja como for, desde logo, eventuais atos praticados pela Administração Pública em juízo, numa linha discrepante da ora preconizada, poderão configurar inaceitável abuso de defesa ou revelar inadmissível tática protelatória (art. 273, II do CPC), sem embargo do enquadramento eventual na hipótese de dano irreparável ou de difícil reparação (273,

4 Vide, por exemplo, o julgamento dos Embargos de Declaração 97.04.11099-5/RS, quando a Quarta Turma do TRF-4 Regiāo entendeu, de ofício, que a embargante (empresa pública) demonstrou caráter procrastinatório, ofendendo o dever de lealdade (CPC, arts. 14 e 17), bem como ao próprio Poder Judiciário. 
I). Em quaisquer dos casos, poder-se-ia cogitar da requerida antecipação da tutela, cuidando-se, é claro, para evitar situações de irreversibilidade. Todavia, a solução mais desejável está em que juiz-relator negue o seguimento do recurso por manifestamente infundado, quando se revelar colidente e incompatível com jurisprudência tranquiila do Supremo Tribunal Federal ou decisão reiterada e incontroversa dos demais Tribunais. Simetricamente, é de se considerar um avanço, embora tímido, a proposta de reforma processual, admitindo (o que, a meu sentir, já se extrai da teleologia do atual sistema) a possibilidade de o relator, em caso de a postulação ter ocorrido em manifesta divergência com orientação pretoriana indiscutível, prover o recurso.

De conseguinte, sem negligenciar em nada os afazeres do cioso agente público, fundamental é reservar a sua preciosa atenção para aquilo que merece ser cuidado, vale dizer, a proteção simultânea do interesse público e da dignidade do cidadão, o qual tem o direito de uma justiça efetiva e prestada em tempo hábil, até para que seja permitido repetir - sua vitória não se converta em miragem ou promessa remota e quimérica.

A estar certa a linha de raciocínio esposada, resplandesce que o legislador infraconstitucional, já naquela altura, equivocou-se - no cotejo com a vontade constitucional —, na formulação do art. 77 da Lei 9.430/96 - , ao apenas facultar ao Poder Executivo a disciplina das hipóteses em que a Administração Tributária federal, relativamente aos créditos baseados em dispositivo declarado inconstitucional por decisão definitiva do STF, poderia abster-se de constituí-los, bem como retificar o seu valor ou declará-los extintos, de ofício, ainda que inscritos em dívida ativa, e, finalmente, formular desistência de ações de execução fiscal ajuizadas, além de deixar de interpor recursos judiciais.

$\mathrm{O}$ real e o autêntico significado deste comando, à base do nosso prisma teleológico, parece ser bem outro e distinto do extraído da mera literalidade, indo além das atecnias do legislador ordinário. Com efeito, não se está perante mera faculdade do agente público, mas de rigoroso e indeclinável dever. A discrição, neste quadro, resulta inteiramente vinculada à decisão definitiva ou indisputável do Poder Judiciário. ${ }^{5} \mathrm{Na}$ mesma senda exegética e por idênticos motivos de fundo, não resulta adequada a diç̧ão literal do art. $4^{2}$ da Lei $9.469 / 97$. Ali se diz que, não havendo a referida Súmula, o Advogado-Geral da União “poderá" dispensar a propositura de ações quando a controvérsia estiver sendo iterativamente decidida pelo Supremo Tribunal Federal ou pelos Tribunais Superiores. Trata-se, tirante casos excepcionalíssimos, de vinculação expressa ao pronunciamento derradeiro ou indisputável.

5 Como bem advertia Georges Vedel in Droit Administratif, Paris, Presses Universitaires de France, 1973, pp. 318-319, inexiste a pura discricionariedade, porquanto " $l$ 'Administration ne se trouve jamais dans une situation de pur pouvoir discrétionaire ou de pure compétence liée." Na mesma senda, Jean Rivero in Droit Administratif, Paris, Dalloz, 1973, p. 82. De seu turno, Ernst Forsthoff in Lehrbuch des Verwaltungsrechts, München, C.H.Beck'sche Verlag, 1973, p.95, conquanto descrevesse o poder discricionário como significando que a ordem jurídica tem por conforme ao Direito tudo que for julgado oportuno, ressalvou que tal poder apenas poderia ser exercido de acordo com o interesse geral e nāo segundo bel-prazer. Sobre os atos administrativos de discricionariedade vinculada aos princípios, vide, outrossim, meu livro Estudos de Direito Administrativo, Malheiros Editores, 2² ed., 1997, pp. 131-152. 
Note-se bem: ao sustentar tal dever, não se está propugnando servilismo nem subserviência, tampouco a ímproba prevaricação. Afinal, em situações-limite, se houver completo e razoável convencimento do desacerto da posição jurisprudencial, mostra-se legítimo procurar alterá-la, mas percorrendo as vias apropriadas, jamais simplesmente pelo bafejo da absurda tese da "falta de caixa". A vinculação do administrador é à lei e ao Direito, sendo que a lei e o Direito têm os seus conteúdos determinados, plasticamente, pelo positivador derradeiro, isto é, pelo Poder Judiciário $^{6}$, o qual, de seu turno, embora em atividade distinta da do legislador, deve exercer conscientemente o papel maiêutico de revelar a elasticidade do Direito objetivo, numa perspectiva tópico-sistemática (naturalmente, sem nenhuma adesão a subjetivismos arbitrários ou a decisionismos irracionais). Como enfatizado, a eficácia do Direito brota da eficácia do intérprete final deste Direito, que nada mais é do que a sociedade através do Judiciário. Somente conquistada e erguida uma harmonia respeitosa entre os poderes, consoante a qual não há lugar para superioridades (apenas distinções funcionais perante o Direito posto), reúnem-se as condições para instaurar, em nosso meio, a eficácia ampliada da Carta e a regeneração da desgastada autoridade pública.

\section{Dos limites hermenêuticos aos "precedentes vinculantes" em relação ao próprio Poder Judiciário: a necessária preservação do controle difuso}

Não se confunda, por obséquio, o até aqui sustentado com a defesa do efeito coativo dos precedentes judiciais perante os órgãos do Poder Judiciário, conquanto o assento constitucional trazido desde a Emenda n. 3 (em relação à Ação Declaratória de Constitucionalidade). Ainda que preconizada, com respeitável tenacidade, por eminentes figuras, parece questionável a adoção do expresso e constrangedor efeito vinculante em relação ao próprio Poder Judiciário, pelas considerações a serem enunciadas, em brevíssima síntese.

Em primeiro plano, mister reconhecer a imperativa prioridade de preservar o sistema de controle difuso, sem prejuízo do consórcio com o modelo concentrado. Em nosso pertinente modelo misto, a vinculação do juiz é ao Direito (rede de princípios e normas ou de regras $^{7}$ ), não precipuamente à lei. Ora, se o precedente vincula apenas e tão-somente tanto quanto uma lei, então se impõe concluir que se encontra destituído do alcance e da hierarquia sistemática dos princípios, sob pena de se cair no unilateralismo da tópica.

6 Vide, a propósito, Eduardo García de Enterría in "Uma nota sobre el interés general como concepto jurídico indeterminado", Revista Española de Derecho Administrativo, n. 89, 1996.

7 Recapitulando a ótica desenvolvida em meu livro A Interpretação Sistemática do Direito, Malheiros Editores, 1995, pp. 21-44, o sistema é uma rede axiológica e hierarquizada de princípios gerais e tópicos, de normas e de valores jurídicos, cuja função $€$ a de, evitando ou superando antinomias, dar cumprimento aos objetivos fundamentais do Estado Democrático, assim como se encontram consubstanciados, expressa ou implicitamente, na Lei Maior. 
Em outras palavras, o conteúdo dos precedentes resta, sempre e sempre, submetido ao inafastável controle difuso, a ser exercitạdo, sem peias ou temores, pelos juízes brasileiros em geral, exatamente como sucede em relação às leis. Não se pode puni-los pelo justo e razoável cumprimento da missão constitucional. Reitere-se: a mantença do controle difuso mostra-se imprescindível à formação de uma ambiência cultural de observância firme do prescrito na Lei Maior, assumida a superioridade constitucionalista em face do chamado legalismo estrito. Depois, mister consignar que $o$ ato de interpretar as normas e os precedentes por analogia implica, acima de tudo, uma permanente hierarquização axiológica, insubsistindo plausibilidade de gélida subsunção estatuária ou axiomático-determinística ${ }^{8}$, uma vez que a todos os aplicadores judiciais está conferido o dever de, fundamentadamente, "positivar" por último (mais até do que concretizar ${ }^{9}$ ) o Direito vigente.

Neste ponto específico, aliás, não se consubstancia diferença nuclear ou essencial entre os sistemas da "common law" e o romanístico-continental, como percebe, de modo quase consensual, a melhor teoria geral contemporânea de interpretação jurídica. Destarte, o "precedente vinculante" será sempre, no mínimo, tão questionável quanto o é no sistema anglo-saxão ${ }^{10}$, no qual o juiz guarda a liberdade para dizer acerca da aplicação, ou não, daquele enunciado ao caso vertente, observando os precedentes, na larguíssima maioria das vezes, ora por inércia, ora por adesão, não propriamente por constrangimento normativo.

De mais a mais, no plano das ponderações de ordem sociológica, força reconhecer que o simples e firme acatamento das decisões judiciais pela Administração Pública, por si só, já desafogaria, sem celeumas, os nossos Tribunais, pois não há dúvida que a Administração Pública converteu-se na grande demandante ou demandada, no contexto que timbra pela imprevisibilidade de sua atuação. Portanto, no tangente ao juiz e à sua independência, a vinculação é apenas aquela que existe, desde sempre, ou seja, a decorrente de acolhimento do precedente por livre e fundamentada conviç̧ão.

Sublinhe-se que tal posicionamento (eminentemente hermenêutico) parece superar o dilema sem fomentar hostilidades e incompreensões que podem desarmonizar o sutil tecido interno do próprio Poder Judiciário: os precedentes vinculam ao juiz tanto quanto as leis, logo devem ser cotejados com o Direito na sua totalidade, exercitado, com a insuprimível liberdade, o controle difuso. Certo, poder-se-ia arrolar

8 Como observa Gustavo Zagrebelsky in La giustizia costituzinale, il Mulino, 1988, p. 51: “Il pensiero giuridico sistematico e dogmatico, per essere compatible con il pensiero o casistico, non deve assumere posizioni rigide che comportino la pietrificazione difensiva dei suoi prodotti contro le novità che la vita del diritto gli presenta come sfide."

9 Sobre a concretização jurídica, vide Konrad Hesse in Grundzuege des Verfassungsrechts der Bundsrepublik Deustchland, Karlsruche, p. 26 e Grenzen der Verfassungswandlung, Berlinm Duncker \& Humblot, 1974.

10 Vide a didática exposição de Peter Messite in Justiça e Juízes nos Estados Unidos in RTRF-4ª Porto Alegre, Livraria do Advogado, 1997, pp. 38-44. Sobre a convergência dos sistemas, sem prejuízo de evidentes peculiaridades quanto às fontes, vide a pesquisa Corpo e Alma da Magistratura Brasileira. Luiz Werneck Vainna e outros, Revan, luperj, 1997, p. 37. 
uma série imensa de argumentos complementares a propósito da leitura que se faz da vinculação dos juízes, mas se deixa de fazê-lo por desbordar da meta do presente estudo. Afinal, o maior objetivo do escrito consiste em grifar a extrema conveniência do acatamento das pacificadas decisões judiciais pela Administração Pública, realçando que o maior beneficiário de semelhante postura, com certeza, não será apenas aquele que litiga atomizadamente contra o Poder Público, mas o contribuinte e, por via de consequiência, $o$ interesse geral.

\section{Conclusões}

Do exposto, convém, especialmente, restar sulcado:

(a) O pronto acatamento das decisões judiciais iterativas pela Administração Pública revela-se decorrência teleológica dos princípios fundamentais que a regem, notadamente os da segurança das relações jurídicas, o da unicidade da jurisdição, $o$ da moralidade, o da confiança e o da economicidade.

(b) É apenas aparente a faculdade prevista nos diplomas citados (Lei n. 9.430/96, art. 77 e Lei 9.469/97, art. $4^{\circ}$ ), mais do que nunca se evidenciando que, em sede de Direito Administrativo, em maior ou menor grau, toda discricionariedade resulta vinculada.

(c) Ao homenagear, acolhendo de modo célere, às orientações jurisprudenciais iterativas (fonte material, por excelência, do Direito), não está a Administração Pública deixando de ser zelosa e independente, mas reservando energia e vigor para os combates verdadeiramente prioritários.

(d) A eficácia vinculante dos precedentes, em relação ao próprio Poder Judiciário, em especial por razões hermenêuticas, deve ser mais propriamente a que deflui apenas da livre e fundamentada adesão, em face da imprescindível manutenção do sistema difuso em convívio fecundo com o modelo concentrado de controle de constitucionalidade. 


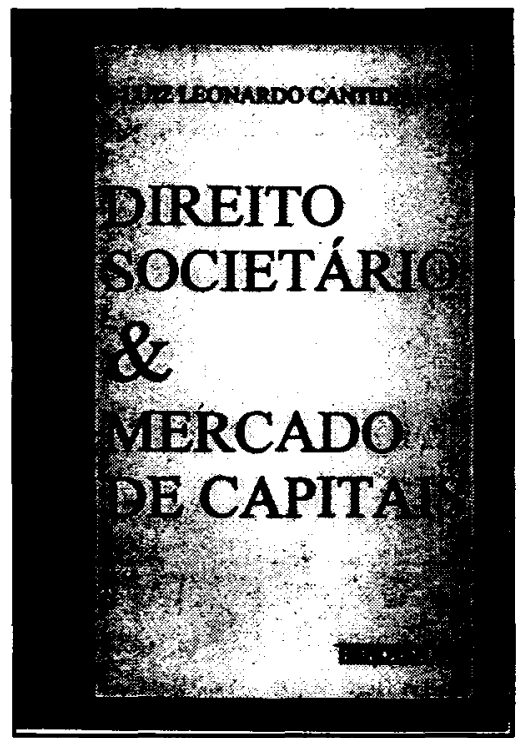

Ref. 0100

Brochura

190 págs.

Form. 14x21

1996

\section{DIREITO SOCIETÁRIO \\ E MERCADO \\ DE CAPITAIS}

\section{Luiz Leonardo Cantidiano}

Fruto de sua experiência profissional, o autor analisa questōes relacionadas às sociedades anônimas e ao mercado de capitais, com que empresários e consultores vêm se defrontando na atual fase do processo de desenvolvimento do país. São abordadas aqui as particularidades que decorrem da alienação do controle de uma companhia, especialmente se aberta. São apontadas também as relaçōes existentes entre o programa de privatização das empresas estatais e o mercado de capitais. 